\title{
EDITORIAL
}

\section{Lessons From Dr Strangelove}

In the early 1980s, a group of visionary physicians founded a medical organization predicated on the advancement of a singular health issue. This society was not one dedicated to patient care in the wilderness, but rather to promote understanding of the health risks of nuclear proliferation. They called themselves the International Physicians for the Prevention of Nuclear War (IPPNW), and their clinical assessment was a sober rebuke to Cold War strategists: "Nuclear war would be the final epidemic; there would be no cure and no meaningful medical response."

By the fall of the Berlin Wall, the IPPNW was 200,000 members strong and had played an instrumental role in promoting the international agreements to ban nuclear test explosions and to close nuclear weapons testing sites and production facilities. Its work was recognized by the Nobel Committee-the 1985 Prize for Peace.

Looking back at the IPPNW, we can see two key factors that led to the organization's widespread appeal:

The physicians spoke with unambiguous clarity in the face of dissonance from multiple sources including governments, lobbyists, and various political entities. The source issues of nuclear proliferation were complex and involved conflicting science, national security concerns, and economic policy. Yet their position was clear and without conditions - the health risks of nuclear war were massive and irrevocable.

They spoke as physicians. Few professions enjoy the privilege of public trust as does medicine. They acted within its best traditions as conduits between society and science and as society's collective health conscience. The persuasive strength of the IPPNW was that they were advocates in white coats. They drew upon the doctor-patient relationship in making their case, and they were able to claim neutral ground within the political rhetoric of the Cold War to advocate for the well-being of humanity.

\section{Our Own Grand Challenge}

In the second decade of the 21st century, we are facing another grand challenge, equally as formidable as that of 30 years ago: that of the extensive, accelerating effects of climate change, environmental degradation, and biodiversity loss. Although policy makers debate causality and mitigation strategies, there is a growing consensus among health care professionals worldwide that environmental change will have an increasingly negative impact on human health, and may very well be the biggest global health threat of the 21 st century. ${ }^{2}$

The math is easy to understand. The global population is expected to increase to 9 billion by 2050 - essentially a $25 \%$ increase in just 40 years. $^{3}$ That means more factories and automobiles, more toxins and pollutants, and increased stress on clean water and arable land. The environmental impact of this population surge will affect most communities on the planet and will threaten the well-being of billions through shifting patterns of disease, extreme weather events, food and water insecurity, shelter vulnerability, and population migrations. Populations already deemed vulnerable through extreme poverty, geographic susceptibility, or poor governance will bear a disproportionate burden, suffering in environments with no resiliency and no safety net upon which to fall back.

There will be no easy solutions, and even the most optimistic scenarios call for long-term strategic thinking, thoughtful resource allocation, and steadfast commitments-sentiments that run countercurrent to societies fueled by quarterly earnings and ever-present election cycles.

Leadership is desperately needed, but few voices have succeeded in unifying over dividing. As the IPPNW has demonstrated, physicians can do much to influence public opinion, yet they have been conspicuously absent in these current debates. That is entirely understandable given the vitriolic politics, the scientific uncertainty, and the subject matter in which physicians have not historically had expertise. And when considering the parallels to 30 years ago, public opinion toward nuclear proliferation during the Cold War was a much more straightforward issue to grasp compared with climate change and biodiversity loss. Likewise, the multifaceted opinions on environmental use from across the planet (industrialized vs. developing nations, global north vs. global south) pose complex challenges to accord. 
Nevertheless, there have increasingly been calls within medicine for physicians to play a greater role in these important discussions. ${ }^{4,5}$ In 2008, the American Medical Association explicitly endorsed the findings of the Fourth Intergovernmental Panel on Climate Change. Few in our profession have chosen to accept this challenge, and action to date has been piecemeal and limited to individual institutions. ${ }^{6}$

\section{A Leadership Vacuum}

The current state of affairs suggests that the Wilderness Medical Society (WMS) has an exceptional opportunity. As the sole physician organization dedicated to medical care in the wilderness, our Society is uniquely well poised to take a leadership role in this field. Our members practice all over the world, and have unsurpassed expertise in providing care in some of the most sensitive ecosystems on the planet. Our professional network extends to geographical extremes, conflict zones, and the most vulnerable populations on earth. We are charged with the welfare of both our patients and the wilderness, and there is no better argument to convince people to advocate for environmental wellness than to educate on the direct link to human health.

The need is there-just consider the current state of public discourse. Across the spectrum of public opinion there exists a vast psychological distance between understanding the threats and initiating action. Environmental dangers are packaged in abstract sound bytes: "parts per million of sulfur dioxide," "the scourge of endocrine disruptors," "Save the Whales!" Across all cultures, there is a disconnect between comprehending the seriousness of environmental degradation and the appetite for policy change and effective personal action. Feeling helpless, citizens abrogate responsibility for change to national governments or other large organizations. Policy makers in turn are left to consider conflicting data and contradictory policies. With an absence of understanding, decisions are undercut by a fear of commitment to any particular course of action, leaving inertia as the best rational choice. And without basic scientific knowledge related to human health, it is difficult for laypeople to distinguish legitimate areas of scientific uncertainty from radical skepticism by a vocal, partisan minority. That can lead to an exaggerated sense of uncertainty, breed hopelessness, and undermine an imperative for action. ${ }^{7}$

It is as educators and respected interlocutors that physicians can play a role. We are society's go-betweens, routinely translating abstract medical science into evidence-based treatment plans. The doctor-patient relationship is one of the most cherished throughout all profes- sions; and the important opportunity to educate society on such profound and widespread health risks should not be overlooked. To help frame the discussion on these difficult issues in terms of human health will allow for a more grounded dialogue. And research in social science has shown that risks identified in terms of human life, such as "your mother's risk of cancer," "your child's risk of asthma," are much more effective fulcrums for change than abstract concepts. ${ }^{7}$

The work of the IPPNW illustrates some key lessons. Their message was clear-the stakes cut to the very viability of our collective well-being, and there was no rationale that could alter that premise. Their motivations were untainted by national politics. Their integrity lay in the representations of physicians from across the world, including both the Soviet Union and the United States. Policy makers could disagree with their conclusions, but they had immense difficulty in assailing their credibility. As physicians, they could claim a rhetorical neutrality in allowing the evidence to speak for itself. And, just as it did 30 years ago, the lack of democratic discourse in many affected nations precludes effective citizen initiative, underscoring the importance of advocacy groups.

Can the WMS assume such a role today? To pursue such a mandate will require vigorous conversation among membership. The mission statement of our Society "To advance healthcare, research, and education related to wilderness medicine" is certainly broad enough to assume a greater role in the issues of environmental change. Would this encompass the premise that human health will increasingly depend on a safe environment and stable climate?

Few of us are environmental scientists- our membership is primarily made up of clinicians. But therein lies an asset. We possess the skill sets to educate on the practical implications of complex biological and social processes. By emphasizing science in terms of health risks that can be readily understood, the WMS has the opportunity to elevate public discourse to a more accurate assessment of risks and benefits.

Many of our colleagues still remain skeptical that such advocacy should fall under our professional responsibilities. They rightly note that embracing an apolitical ethos, even one anchored on the best available science, can easily be construed as a political stance. An opposite viewpoint recalls the famous General Charles de Gaulle reply when asked why he would risk his reputation to consider running for office: "[Because] politics is too serious a matter to be left to the politicians."

Indeed, the stakes are serious. Yet, with the dual privilege of a professional commitment to patients and to the wilderness environment, WMS members are uniquely qualified to assume a leadership role. And the lessons from history would suggest that a physician's potential to educate and 
influence discussion should not be underestimated. The founders of the IPNWW were not nuclear engineers or policymakers; they were clinicians who had bold thoughts that changed the world. WMS members-be they in Nepal, the Mountain West, or New York City-should feel likewise empowered.

Jay Lemery, MD Department of Emergency Medicine Weill Cornell Medical College New York, NY

\section{References}

1. Faunce TA. Pilgrims in Medicine: Conscience, Legalism and Human Rights. Leiden, Netherlands: Brill Academic Publishers; 2005:178.

2. World Health Organization. Protecting Health From Climate Change. Geneva, Switzerland: WHO Press; 2009.
3. United Nations Department of Economic and Social Affairs Population Division. Population, Environment and Development: The Concise Report. New York, NY: United Nations; 2001.

4. Roberts S. Doctors and climate change. Lancet. 2010;376: 1801-1802.

5. Auerbach P. Physicians and the environment. JAMA. 2008; 299:956-958.

6. American Medical Association. Resolution on global climate change and human health. Resolution 430, A-08; 279294. 2008. Available at: http://www.ama-assn.org/ resources/doc/hod/i08csaphreports.pdf. Accessed May 30, 2011.

7. Pidgeon N, Fischhoff B. The role of social and decision sciences in communicating uncertain climate risks. Nature Climate Change. 2011;1:35-41.

8. O'Brien P. Politicized humanitarianism: A response to Nicolas de Torrente. Harvard Human Rights Journal. 2004; $17: 31$. 